\title{
SEISMIC POTENTIAL OF FAULTS IN THE GRANADA BASIN (BETIC CORDILLERA, SPAIN)
}

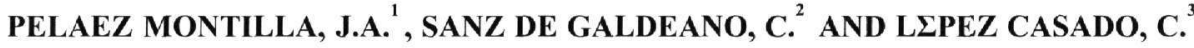

\begin{abstract}
A fault database has been created for the Granada basin (S Spain) concerning seismic potential in this area. The fault lines have been entered as well as their geometry and displacement rate, when known from accumulated displacement. Empirical relationships have been used between the length or surface of the faults and the maximum magnitude that they can generate. No palaeoseismic recurrence intervals are known, nor palaeoseismic estimates for displacements during earthquakes.
\end{abstract}

KEY WORDS: Seismic potential of faults, Granada basin, Betic Cordillera.

\section{INTRODUCTION}

The Granada basin is one of the most active seismic zones of the Iberian Peninsula, in terms of both the number and size of earthquakes. Historically, some of the most destructive earthquakes in the Peninsula took place in this region. Therefore, many studies have been made to calculate seismic hazard, making the information in this zone one of the most complete and of the best quality in Spain.

In the present work, a database has been established to indicate the fundamental characteristics of the faults in this region, both geological and in terms of seismic potential. This database is meant to serve future evaluations of seismic hazard, as in other works (e.g. WGNCEP, 1996; CDC-DMG, 1996).

\section{METHODOLOGY}

The study began with the cartography of the set of faults known in the Granada basin, using the geological maps of the region, though the fault lines have in many cases been corrected with our own data. The main information that was added is indicated below.

Fault lines and total length. The location of each fault and their trace on the surface are needed in any evaluation of seismic hazard, as well as in determining different derived geometric parameters, such as the total fault length. Given that generally no other type of reliable information (seismic or palaeoseismic) is available, the total length of the fault determined from its trace is considered the greatest rupture capable of generating the fault. Hence, this value is used to work with relationships between the length of the rupture and the magnitude.

The database was started with a set of 507 faults which are prone to generate earthquakes or potentially active. Their distribution is shown in Figure 1.

Fault depth. In contrast to previous works in which similar efforts were made to study the seismic potential of other areas, and where the lack of information makes it necessary to consider all the faults of equal depth, in the present work, we seek to establish, if not the depth of each fault, at least a minimum value. In order to do so, we used associated seismic data, seismic profiles and known geological data. The obtained estimates may have a significant error.

From this value, together with the length and dip, we estimated a lower limit for the fault-plane surface, which was also used to estimate the maximum magnitude that the fault could generate. The dip used was that detected on the surface, but numerous faults in the Granada basin have listric geometry. This circunstance has been taken into account in some cases.

Slip rate. To calculate this parameter, we considered the displacement, generally vertical, undergone by

1. Department of Physics. High Technical College. University of Jatn. C/Virgen de la Cabeza, 2. 23071 - Jain (Spain). Email: japelaez@ujaen.es

2. Andalusian Institute of Earth Sciences. CSIC - University of Granada. Faculty of Sciences. Campus de Fuentenueva. 18071 - Granada (Spain). Email: csanz@ugr.es

3. Department of Theoretical and Cosmos Physics. Faculty of Sciences. University of Granada. Campus de Fuentenueva. 18071 - Granada (Spain). Email: clcasado@ugr.es 


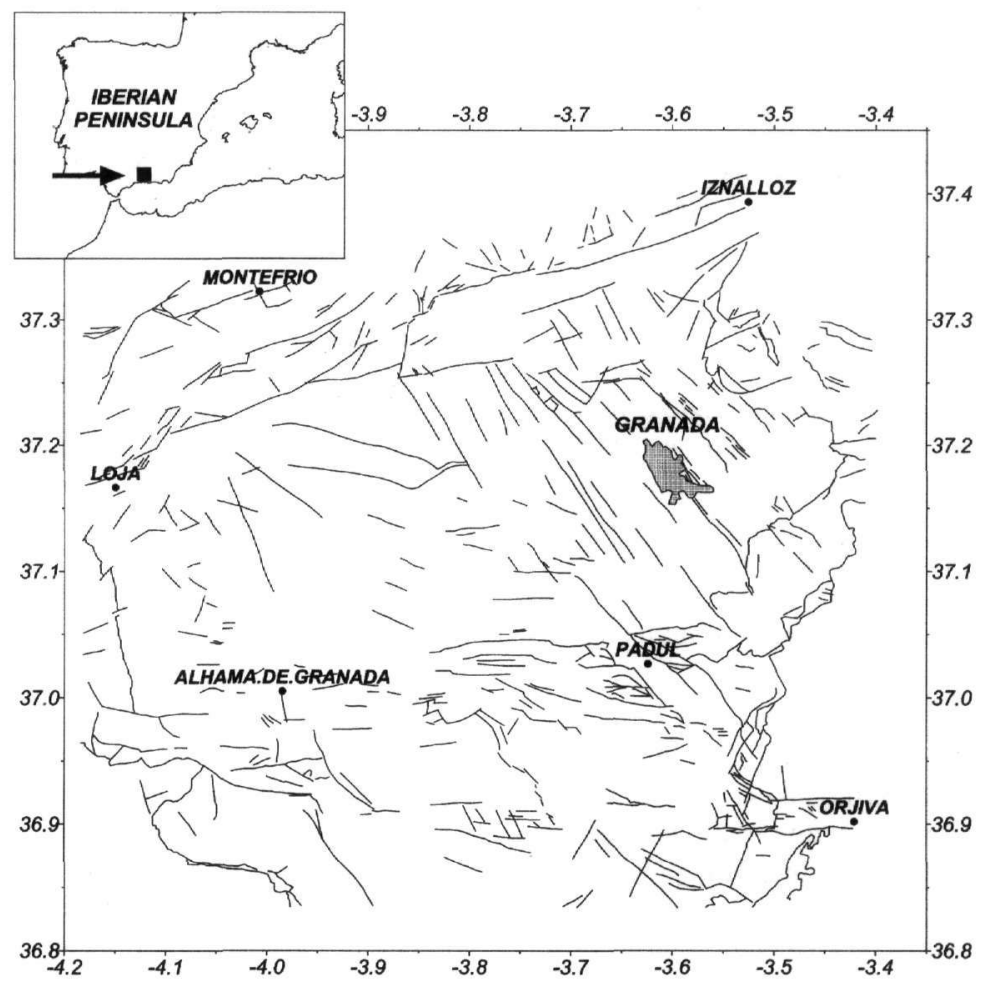

Figure 1. Distribution of the faults in the Granada basin and its surroundings, digitized for this work, which are potentially active.

various reference levels. The most frequently used is that of Tortonian marine calcarenites deposited some 8 Myr and which now reach diverse heights in the basin. The estimate of this motion and the time involved gives average values of the rate of the fault displacement. In some cases, the Pleistocene levels enable the determination of displacement values. In some cases, directly tectonic features (escarpment height) and geomorphological characteristics provide estimates of slip rate of the fault blocks.

Maximum magnitude. To estimate the maximum magnitude that each fault is capable of generating we used different relationships between the maximum magnitude and the length or surface area of the fault. It was also possible to include these in the estimate of the maximum magnitude of the slip rate, as proposed in recent works. In this way, we calculated several values that enable us to verify the consistency of the results.

We estimated the error of the maximum magnitude obtained. For this, given that the parameters appearing in the different lineal relationships proposed are accompanied by their respective variance, simulations were performed using the Monte Carlo method when determining the variance of the estimated result.

The relationships used were: first, that proposed by Wells \& Coppersmith (1994) between the moment magnitude $\left(M_{W}\right)$ and the length of the surface rupture $(l)$

$$
M_{w}=a+b \cdot \log (1)
$$

Also, we used the one proposed by these authors between the moment magnitude and the rupture area $(A)$

$$
M_{w}=a+b \cdot \log (A)
$$

This latter relationship is statistically more robust than the former, in the sense that a greater number of earthquakes was used to estimate the parameters and to establish the relationship, and as a result the errors were slightly lower.

Finally, we also used the relation proposed by Anderson et al. (1996) between the moment magnitude, the length of the surface slip and the slip rate $v$ of the fault

$$
M_{w}=a+b \cdot \log (1)-c \cdot \log (v)
$$


With this relationship, since it includes the fault-slip rate, we attempt to improve the fit between $M_{W}$ and $l$, reducing somewhat the maximum magnitude expected for faults with high slip rates.

Return period. It would be desirable to determine the return period for a given magnitude using the palaeoseismic information by studying the displacements detected in the fault and taking into account the epochs on which these occurred, but in this region such information is scant.

To calculate the return period $t$, we used an approximation based on empirical relationships. The expression used was

$$
t=D_{V}
$$

where $v$ is the slip rate, known for at least the main faults in the region. This is determined from the displacement detected in the fault during a given time interval, although in some cases it is not the current value for this variable. The variable $D$ is the average coseismic slip, which again would be useful to know in the fault from palaeoseismicity (movement that has generated a certain earthquake in the fault). From the definition of seismic moment $\left(M_{o}\right)$

$$
M_{0}=\mu \cdot A \cdot D
$$

where $\mu$ is the rigidity modulus an $A$ the surface rupture, we can calculate the displacement $D$ that caused an earthquake with seismic moment $M_{o}$, or, what is equivalent, we can use the known relationship of Hanks \& Kanamori (1979)

$$
M_{w}=\frac{2}{3} \log M_{0}-10.7
$$

to calculate the value of $D$ that causes an earthquake of moment magnitude $M_{W}$.

With a plot representing for a given fault the logarithm of the return period against the moment magnitude, in all cases we find a straight line with a ${ }_{2}^{3}$ slope (the inverse of the slope in the relationship between $M_{W}$ and $\log M_{o}$ ) and where the ordinate at the origin is a function of the logarithm of the product $A \cdot v$.

The slip rate, although having little influence on the maximum magnitude that a fault may generate, considerably affects the change in the return of a given earthquake, since it will reach before the average coseismic slip.

\section{RESULTS: FAULTS WITH THE HIGHEST SEISMIC POTENTIAL AND SLIP RATE}

Table 1 shows the potentially most dangerous faults in the Granada basin. For each fault the type is indicated as well as the total length of the surface line $(l)$, depth $(d)$, dip(d), fault-slip rate $(v)$, maximum magnitude capable of being generated together with its variance, period of return $(t)$ calculated/estimated for the magnitudes

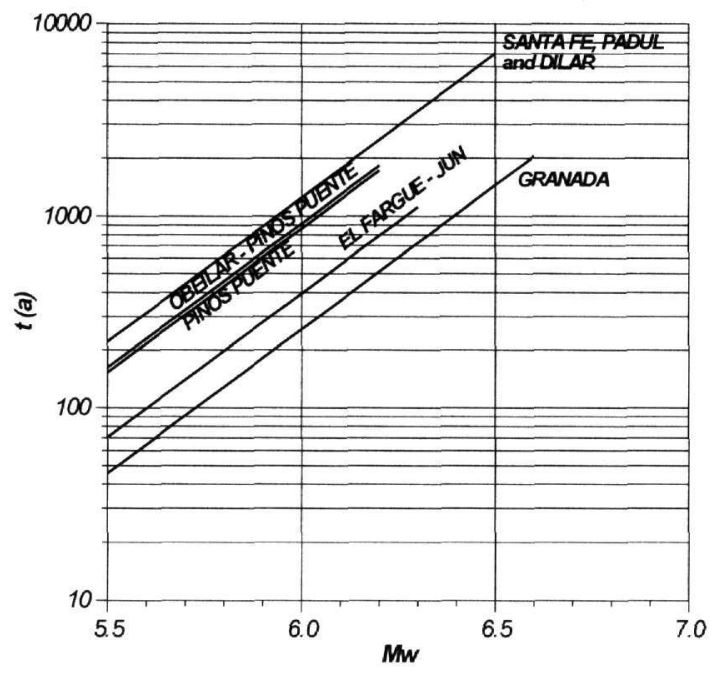

Figure 2. Return period (t) as a function of the moment magnitude $\left(\mathrm{M}_{\mathrm{w}}\right)$ for the faults in the Granada basin where a smaller value of this variable has been obtained. The curves has been plotted up to the maximum magnitude that the fault is able to produce. 
6.0 and $6.5 M_{W}$, and towns near the fault line.

Figure 2 shows the return period as a function of the magnitude for the faults in Table 1, in which a lower value for this variable was found. Because of the lack of data for the slip rate in some faults, the return periods could not be determined in those cases.

According to these results, the maximum magnitude expected is of the order of $6.9 M_{s}$ in the case of the fault called Iznalloz, which has a length of about $19 \mathrm{~km}$. Many other faults could also generate magnitudes exceeding 6.0. However, the faults that present higher slip rates are, from north to south, those known as: Obtilar-Pinos Puente, Pinos Puente, El Fargue-Jun, Granada, Belicena-Alhendvn, Dvlar, Padul, Padul-Dïrcal and Lanjaron.

\section{CONCLUSIONS}

The present work provides an assessment of different parameters of faults in the Granada basin related to their seismic potential, although this evaluation has certainly some limitations. First, the existing network of faults is not completely known, because there are faults that are not visible on the surface. Nevertheless, we believe that the main faults are included in this work. Another limitation, discussed above, is that in general, we do not know in depth the geometry of the faults, as well as their continuity or variation in dipping. The lack of general palaeoseismic data hampers estimates of the return periods.

Overall, the final results show the average return periods that can be expected in the Granada basin, also indicating the main faults that are currently active. These, from north to south are: Obilar-Pinos Puente, Pinos Puente, El Fargue-Jun, Granada, Belicena-Alhendvn, Dvlar, Padul, Padul-Dïrcal and Lanjaron. Many of these faults could conceivably produce earthquakes with magnitudes exceeding $6.0 M_{W}\left(I_{M S K} \approx \mathrm{IX}\right)$, though this is not the expected scenario, as energy is dissipated in earthquakes of lower magnitude, as it appears to happen in the Granada-Sierra Elvira area.

\section{REFERENCES}

ANDERSON, J.G., WESNOUSKY, S.G. AND STIRLING, M.W. (1996). Earthquake size as a function of fault slip rate. Bull. Seism. Soc. Am., 86, 683-690.

CDC-DMG (California Department of Conservation - Division of Mines and Geology) (1996). California fault parameters. CDC-DMG Open-File Report 96-08.

HANKS, T.C. AND KANAMORI, H. (1979). A moment-magnitude scale. J. Geophys. Research, 84, 2348-2350.

WELLS, D.L. AND COPPERSMITH, K.J. (1994). New empirical relationships among magnitude, rupture length, rupture width, rupture area, and surface displacement. Bull. Seism. Soc. Am., 84, 974-1002.

WGNCEP (Working Group on Northern California Earthquake Potential) (1996). Database of potential sources for earthquakes larger than magnitude 6 in northern California. USGS Open-File Report 96-705. 


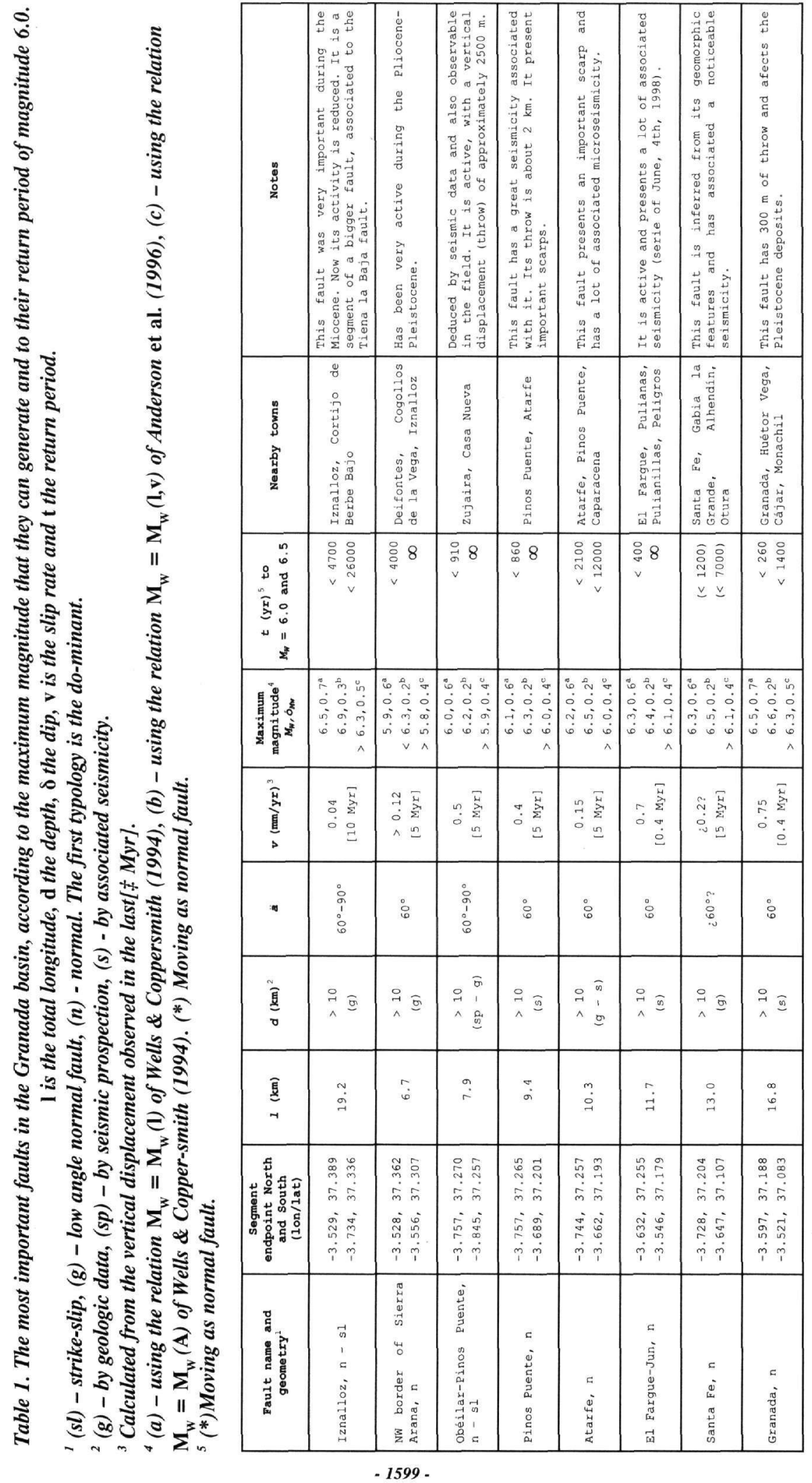




\begin{tabular}{|c|c|c|c|c|c|c|c|c|c|c|}
\hline 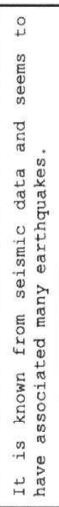 & 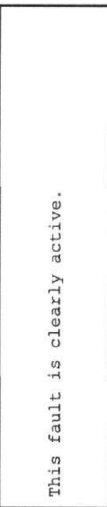 & 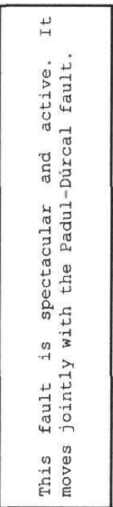 & 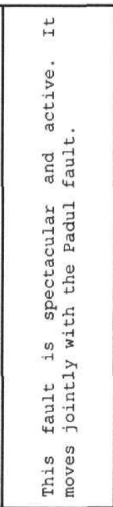 & 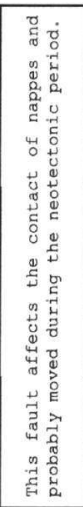 & 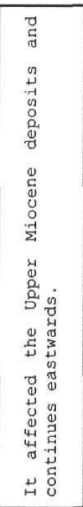 & 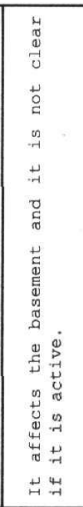 & 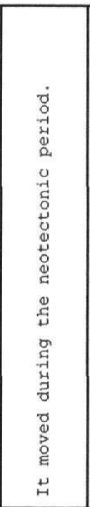 & 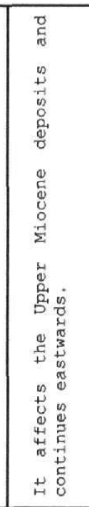 & 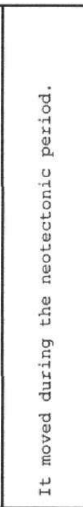 & 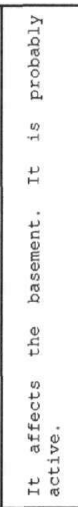 \\
\hline 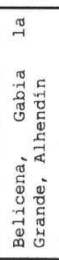 & 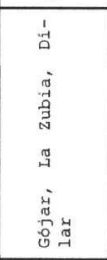 & 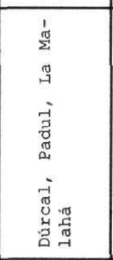 & 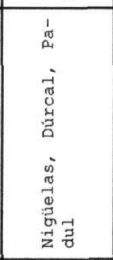 & 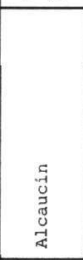 & 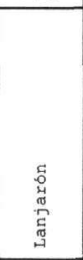 & 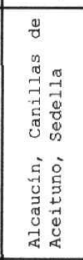 & 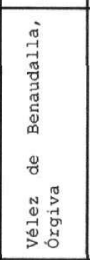 & 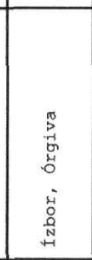 & 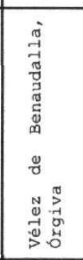 & 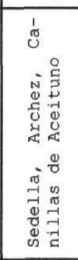 \\
\hline 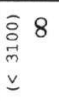 & 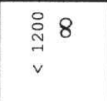 & 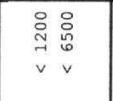 & 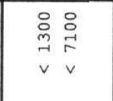 & $\begin{array}{l}\text { o } \\
\text { pr } \\
\text { v }\end{array}$ & 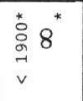 & 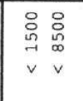 & 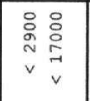 & 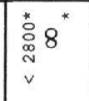 & 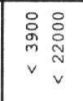 & 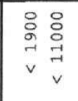 \\
\hline 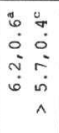 & 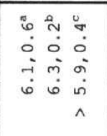 & 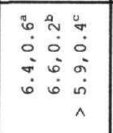 & 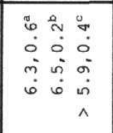 & 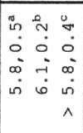 & 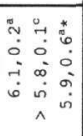 & 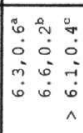 & 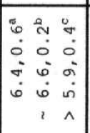 & 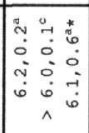 & 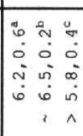 & 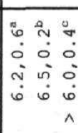 \\
\hline 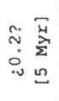 & 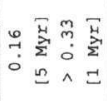 & 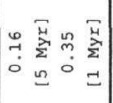 & 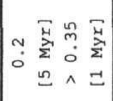 & 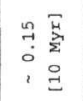 & 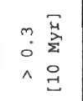 & 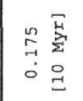 & 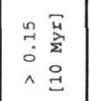 & 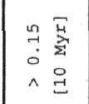 & 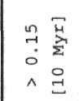 & 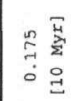 \\
\hline$:$ & 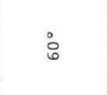 & $\begin{array}{l}: \\
\dot{0} \\
i \\
0 \\
i\end{array}$ & $\begin{array}{l}: \\
0 \\
\vdots \\
\vdots \\
\vdots \\
0\end{array}$ & $\begin{array}{l}0 \\
0 \\
1 \\
0 \\
0 \\
m\end{array}$ & : & $\begin{array}{l}0 \\
\vdots \\
1 \\
\vdots \\
0 \\
0\end{array}$ & $\begin{array}{l}\dot{m} \\
\text { v }\end{array}$ & $\therefore$ & $\begin{array}{l}\stackrel{0}{p} \\
v\end{array}$ & $\begin{array}{l}\vdots \\
\vdots \\
\vdots \\
\vdots \\
0 \\
0\end{array}$ \\
\hline${ }_{\wedge} \stackrel{\bar{\Xi}}{\varrho}$ & $\therefore$ 으 & ${ }_{1}^{n}$ का & 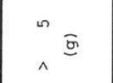 & 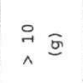 & ${ }_{1}^{\circ}$ 可 & 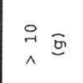 & 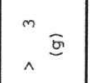 & ${ }_{1}^{\circ}$ 可 & ${ }^{m}$ कु & $\stackrel{1}{1}_{1}$ 흐 \\
\hline م. & $\underset{\infty}{m}$ & ֻั & $\stackrel{\circ}{\ddot{m}}$ & $\stackrel{m}{m}$ & $\stackrel{\circ}{\dot{\varphi}}$ & 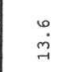 & $\vec{j}$ & $\stackrel{\infty}{\infty}$ & $\stackrel{\ddot{c}}{\circ}$ & 京 \\
\hline 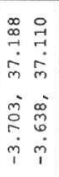 & 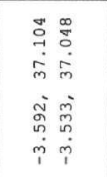 & 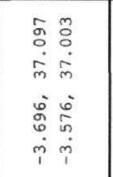 & 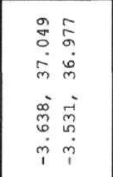 & 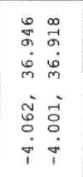 & 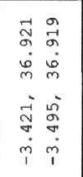 & 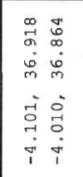 & 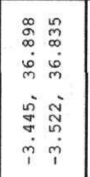 & 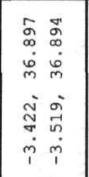 & 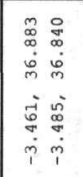 & 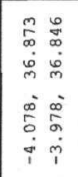 \\
\hline 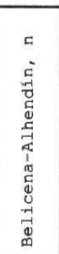 & $\begin{array}{l}\text { s } \\
\text { cं } \\
\text { जี }\end{array}$ & : & 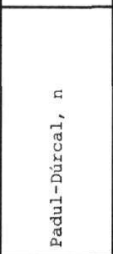 & 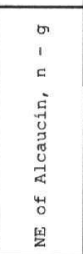 & 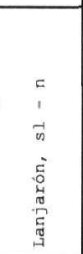 & 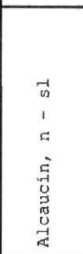 & 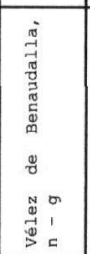 & 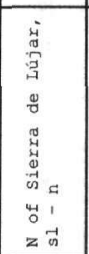 & 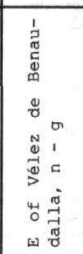 & 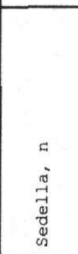 \\
\hline
\end{tabular}

